\title{
Extracellular and intraneuronal HMW-AbetaOs represent a molecular basis of memory loss in Alzheimer's disease model mouse
}

\author{
Ayumi Takamura ${ }^{1,2}$, Yasuhide Okamoto ${ }^{1,3}$, Takeshi Kawarabayashi ${ }^{2}$, Tatsuki Yokoseki ${ }^{3}$, Masao Shibata ${ }^{3}$, \\ Akihiro Mouri', Toshitaka Nabeshima ${ }^{4}$, Hui Sun ${ }^{1}$, Koji Abe ${ }^{5}$, Tsuneo Urisu ${ }^{6}$, Naoki Yamamoto ${ }^{1}$, Mikio Shoji², \\ Katsuhiko Yanagisawa', Makoto Michikawa' and Etsuro Matsubara ${ }^{1,2^{*}}$
}

\begin{abstract}
Background: Several lines of evidence indicate that memory loss represents a synaptic failure caused by soluble amyloid $\beta$ ( $A \beta$ ) oligomers. However, the pathological relevance of $A \beta$ oligomers ( $A \beta O s$ ) as the trigger of synaptic or neuronal degeneration, and the possible mechanism underlying the neurotoxic action of endogenous $A \beta O s$ remain to be determined.

Results: To specifically target toxic AßOs in vivo, monoclonal antibodies (1A9 and 2C3) specific to them were generated using a novel design method. 1A9 and 2C3 specifically recognize soluble ABOs larger than 35-mers and pentamers on Blue native polyacrylamide gel electrophoresis, respectively. Biophysical and structural analysis by atomic force microscopy (AFM) revealed that neurotoxic 1A9 and 2C3 oligomeric conformers displayed non-fibrilar, relatively spherical structure. Of note, such $A \beta O$ s were taken up by neuroblastoma (SH-SY5Y) cell, resulted in neuronal death. In humans, immunohistochemical analysis employing 1A9 or 2C3 revealed that 1A9 and 2C3 stain intraneuronal granules accumulated in the perikaryon of pyramidal neurons and some diffuse plaques. Fluoro JadeB binding assay also revealed 1A9- or 2C3-stained neurons, indicating their impending degeneration. In a longterm low-dose prophylactic trial using active $1 \mathrm{~A} 9$ or 2C3 antibody, we found that passive immunization protected a mouse model of Alzheimer's disease (AD) from memory deficits, synaptic degeneration, promotion of intraneuronal $\mathrm{ABO}$, and neuronal degeneration. Because the primary antitoxic action of $1 \mathrm{~A} 9$ and $2 \mathrm{C} 3$ occurs outside neurons, our results suggest that extracellular $A \beta O$ s initiate the $A D$ toxic process and intraneuronal $A \beta O s$ may worsen neuronal degeneration and memory loss.
\end{abstract}

Conclusion: Now, we have evidence that HMW-A $3 \mathrm{O}$ s are among the earliest manifestation of the AD toxic process in mice and humans. We are certain that our studies move us closer to our goal of finding a therapeutic target and/or confirming the relevance of our therapeutic strategy.

\section{Background}

Alzheimer's disease $(\mathrm{AD})$ represents the so-called "storage disorder" of amyloid $\beta(A \beta)$. The AD brain contains soluble and insoluble $A \beta$, both of which have been hypothesized to underlie the development of cognitive deficits or dementia [1-3]. The steady-state level of $A \beta$ is controlled by the generation of $A \beta$ from its precursor, the degradation of $A \beta$ within the brain, and transport of $A \beta$ out of the

\footnotetext{
* Correspondence: etsuro@cc.hirosaki-u.ac.jp

'Department of Alzheimer's Disease Research, Research Institute, National

Center for Geriatrics and Gerontology, Aichi, Japan

Full list of author information is available at the end of the article
}

brain. The imbalance among three metabolic pathways results in excessive accumulation and deposition of $A \beta$ in the brain, which may trigger a complex downstream cascade (e.g., primary amyloid plaque formation or secondary tauopathy and neurodegeneration) leading to memory loss or dementia in AD. Accumulated lines of evidence indicate that such a memory loss represents a synaptic failure caused directly by soluble $A \beta$ oligomers (A $\beta \mathrm{Os}$ ) [4-6], whereas amyloid fibrils may cause neuronal injury indirectly via microglial activation [7]. Thus, the classical amyloid cascade hypothesis [8] underwent a modification in which the emphasis is switched to the intermediate

\section{() Biomed Central}


form of $A \beta$ such as $A \beta O$ O [9-12], rather than fibrillar $A \beta$ [7]. If this were the case, therapeutic intervention targeting $\mathrm{A} \beta \mathrm{Os}$ may be effective in blocking this pathogenic cascade. The outcome of a recent human AN-1791 trial confirmed that plaque removal did not prevent the progression of neuronal degeneration [13], supporting this hypothesis.

However, the distinct assembly states of $A \beta O$ Os remain to be elucidated. Several forms of $A \beta O$ s have been found to be neurotoxic, from LMW-oligomers (dimers, trimers, and tetramers) disrupting memory function $[14,15]$, synaptic function $[15,16]$ and long-term potentiation (LTP) [14,17], to dodecamers affecting memory [18]. In addition, $A \beta$-derived diffusible ligands (or ADDLs) $[9,19]$, globulomers [11], fibrillar $A \beta$ oligomers $[20,21]$, and toxic soluble $A \beta$ assembly (TA $\beta$ ) [22] have been shown to be highly synaptotoxic or neurotoxic. Recently, a particular form of $\mathrm{A} \beta \mathrm{O}$, named the native amylospheroids [23], has been isolated from AD brains and found to induce neuronal loss through its binding to synaptic targets [24].

In this study, we chose a prophylactic passive immunization as a tool to define not only the pathological relevance of $\mathrm{A} \beta \mathrm{Os}$ as the trigger of synaptic or neuronal degeneration, but also the possible mechanism underlying the neurotoxic action of endogenous $\mathrm{A} \beta \mathrm{OS}$. To address this issue, we successfully generated monoclonal $1 \mathrm{~A} 9$ and $2 \mathrm{C} 3$ antibodies using a novel design method. When extracellular high-molecular-weight (HMW)-A $\beta$ Os were controlled by $1 \mathrm{~A} 9$ or 2C3 in Swedish-type amyloid precursor protein (APP) transgenic mice (Tg2576), we demonstrated that synaptic/neuronal degeneration or accumulation of intraneuronal $A \beta O$ s was effectively prevented. These results argue for a role of both extracellular and intracellular HMW-A $\beta O s$ in the induction and progression of synaptic or neuronal degeneration and provide a potential explanation for the extracellular one as the primary molecular basis for a toxic process.

\section{Results}

\section{Generation of A $A$ oligomer-specific monoclonal antibodies}

Since the removal of $A \beta M$ s is critical for the preparation of antigens to obtain $\mathrm{A} \beta \mathrm{O}$-specific antibodies, we isolated SDS-stable $A \beta$ tetramers alone without any contamination of $A \beta$ trimers and $A \beta M$ s by SDS-PAGE (Figure 1A). After in vivo immunization with the gel containing the $A \beta$ tetramer alone, positive hybridoma supernatants were screened by dot blot analysis. Among positive supernatants $(16 / 400$, positive $\%=4 \%)$, two clones, namely, $1 \mathrm{~A} 9$ and $2 \mathrm{C} 3$, were generated from a mouse that produced IgG2b. As shown by dot blot analysis, both $1 \mathrm{~A} 9$ and $2 \mathrm{C} 3$ recognized soluble $\mathrm{A} \beta \mathrm{Os}$ $(100,000$ g supernatant (sup) of 4-h-incubated mixture,
Figure $1 \mathrm{~B}$ and $1 \mathrm{C})$, not $\mathrm{A} \beta \mathrm{Ms}$ (560,000 g sup of seedfree preparation, Figure $1 B)$ or $A \beta$ fibrils $(100,000$ g pellet of 120-h-incubated mixture, Figure $1 C$ ), in contrast with 4G8 (Figure 1B and 1C). The generation of A11or 2C3-immunoreactive oligomers preceded that of 1A9-immunoreactive oligomers (Figure 1B). The 1A9 conformer displayed a different pattern of its time course, showing the highest stability in the oligomeric assembly state (Figure 1B).

We further assessed the precise size of 1A9- or 2C3immunoreactive $\mathrm{A} \beta \mathrm{O}$. Blue native polyacrylamide gel electrophoresis (BN-PAGE), a charge shift method of electrophoresis, was carried out to determine the molecular mass and native oligomeric status of the 4-h-incubated mixture. As shown in Figure 1D, the native $A \beta$ species exhibit $A \beta$ monomers, low-molecular-weight (LMW)oligomers (dimers, trimers, tetramers, pentamers, and heptamers), and a high-molecular-weight (HMW)-oligomeric smear with molecular masses ranging in sizes from 66 to $720 \mathrm{kDa}$ (Figure 1D). Immunoblot analysis employing monoclonal $1 \mathrm{~A} 9$ revealed its immunoreactivity with $\mathrm{A} \beta$ species corresponding to HMW-oligomeric smear of 480 to $1048 \mathrm{kDa}$ (Figure 1E), whereas 2C3 immunoreacted with $A \beta$ species corresponding to a broad smear of 146 to $1048 \mathrm{kDa}$ plus minute amounts of pentamers (Figure 1E). The anti-oligo A11 immunoreacted with native $A \beta$ species corresponding to a HMW-smear ranging in sizes from 242 to $1000 \mathrm{kDa}$ (Figure 1E), whereas monoclonal 4G8 detected $A \beta$ oligomers larger than tetramers (Figure $1 E$ ). The combination of two-dimensional native/SDS-PAGE and 4G8-immunoblot analysis revealed that 2\% SDS disaggregates $\mathrm{HMW}-\mathrm{A} \beta \mathrm{O}$ s down to monomers and LMWoligomers in addition to SDS-stable HMW-oligomers with molecular masses corresponding to those of 8 40-mers (Figure 1F). These findings suggest that the assignment of oligomer size is dependent on the method of evaluation. Indeed, monoclonal 4G8 detected all the $A \beta$ species separated, whereas anti-oligo A11, 1A9, or 2C3 immunoreacted with SDS-stable 15-mers to 40-mers under our denaturing conditions tested (Figure 1G), indicating that $1 \mathrm{~A} 9$ or $2 \mathrm{C} 3$ is indeed specific to $\mathrm{A} \beta \mathrm{Os}$.

\section{Characterization of neurotoxic $\mathrm{A} \beta \mathrm{O}$ s}

We further assessed the morphology of neurotoxic $A \beta O$ s. After 0-h-, 2-h- or 4-h-incubation at $37^{\circ} \mathrm{C}$, we tested the bioactivity of each incubated mixture $(25 \mu \mathrm{M})$ by incubating NGF-differentiated PC12 (PC12N) cells [22] at $37^{\circ} \mathrm{C}$ for $48 \mathrm{~h}$. Surprisingly, Live/Dead two-color fluorescence assay [22] revealed that 2-h- or 4-h-preformed A $\beta 42$ assembly decreased the toxic activity, whereas depletion of "insoluble" $A \beta O$ s and concentration of "soluble" $A \beta O$ Os fully restored the toxic activity, similarly to that of $A \beta 42$ assembly formed from seed-free fresh peptide $(0 \mathrm{~h})$ (Figure $2 \mathrm{~A})$. These data indicated that 
A

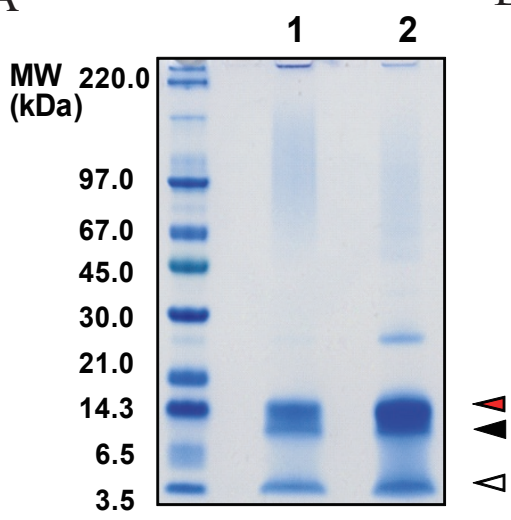

C

oligomers fibrils

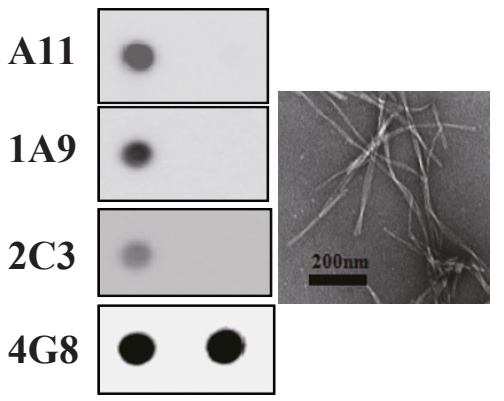

$\mathrm{F}$

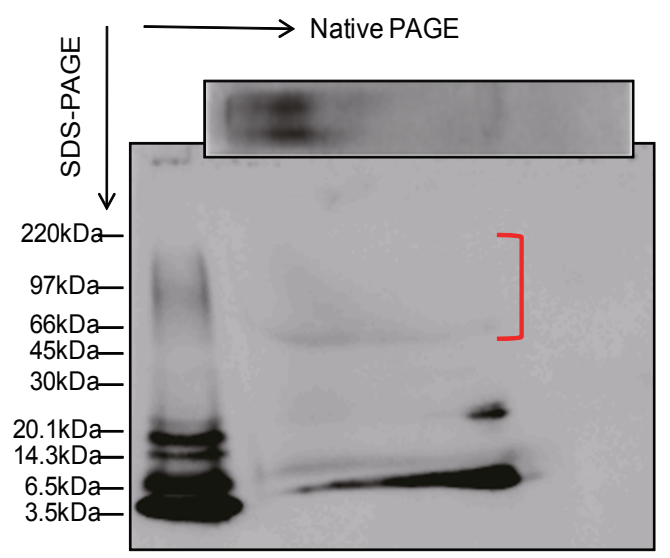

$\mathrm{B}$

$\begin{array}{lllllllll}\text { hour } & 0 & 2 & 4 & 8 & 12 & 24 & 48 & 72\end{array}$

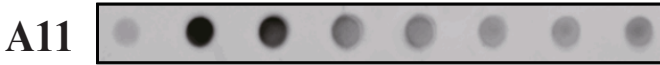

$1 \mathrm{A9}$

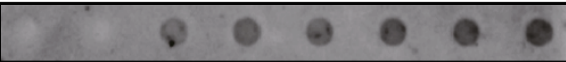

$2 \mathrm{C} 3$

$4 \mathrm{G8}$

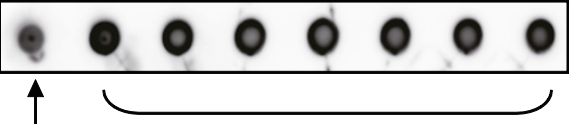

monomer

oligomer

\section{$540,000 \mathrm{gsup}$}

D

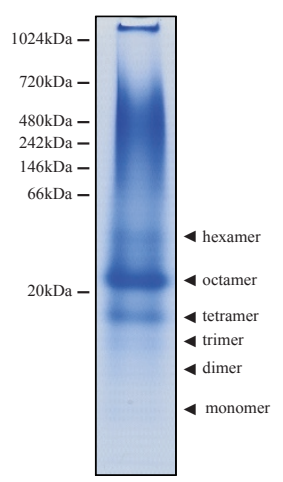

E

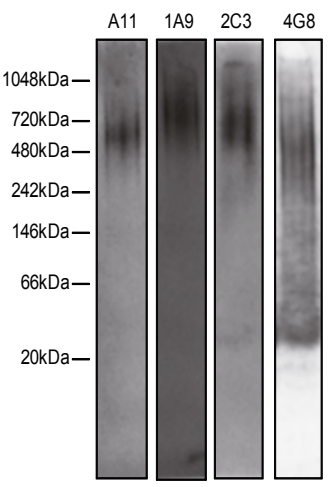

G

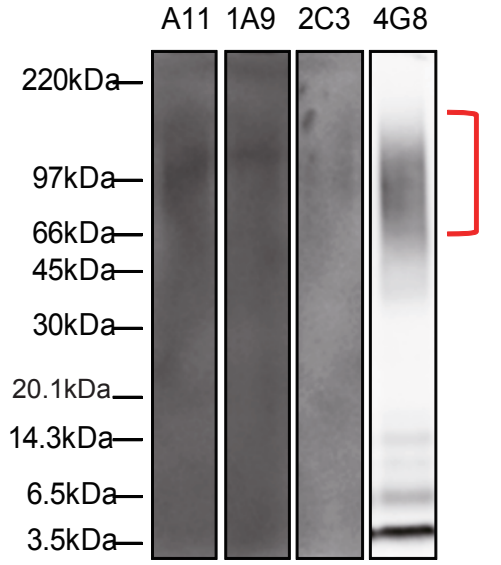

Figure 1 Generation and characterization of oligomer-specific antibody. (A) Electrophoresis of immunogen. SDS-PAGE was performed to isolate the A $\beta$ 1-42 tetramer (red closed arrowhead) alone without any contamination by the A $1-42$ trimer (black closed arrowhead) and $A \beta 1-42$ monomer (opened arrowhead). Lane 1, A $1-42$ dissolved in 10 mM phosphate buffer; lane 2, A 1-42 dissolved in distilled deionized water. (B) A $1-42$ oligomer formation was observed as a function of time. $A \beta 1-42$ monomer $(25 \mu \mathrm{M})$ incubated at $37^{\circ} \mathrm{C}$ for the indicated time $(0-72 \mathrm{~h})$ were spotted on nitrocellulose membrane and subjected to a dot blot assay using A11 (1:100), 1A9 (1:50), 2C3 (1:50), or 4G8 (1:1000). (C) In this dot blot assay (left half of panel C), $1 \mu \mathrm{g}$ of soluble $A \beta 42$ oligomers $\left(100,000 \mathrm{~g}\right.$ sup for 4-h-incubation at $37^{\circ} \mathrm{C}$ ) and $\mathrm{A} \beta 42$ fibrils ( $100,000 \mathrm{~g}$ pellets for 120-h-incubation at RT) were applied on a nitrocellulose membrane and probed with A11, 1A9, 2C3, or 4G8. EM image of fibrils (right half of panel C). (D) Characterization of A 1 1-42 oligomers under nondenaturing conditions. A 1 1-42 monomer ( $25 \mu \mathrm{M})$ incubated at $37^{\circ} \mathrm{C}$ for $4 \mathrm{~h}$ was separated on 16\% BN-PAGE. (E) Separated peptides under nondenaturing conditions were also subjected to immunoblot analysis using A11, 1A9, 2C3, and 4G8. (F) The $100000 \mathrm{~g}$ sup of 4-h-incubated mixture of AB1-42 monomer (25 $\mu \mathrm{M})$ was subjected to two-dimensional native/SDS-PAGE, followed by 4G8-immunoblot analysis. SDS-stable 15 40-mers are indicated (] (red)). (G) Immunodetection of 4-h-incubated mixture of A 1 -42 monomer $(25 \mu \mathrm{M})$ under denaturing conditions probed with A11, 1A9, 2C3, and 4G8. SDS-stable 15 40-mers are indicated (] red). 
A
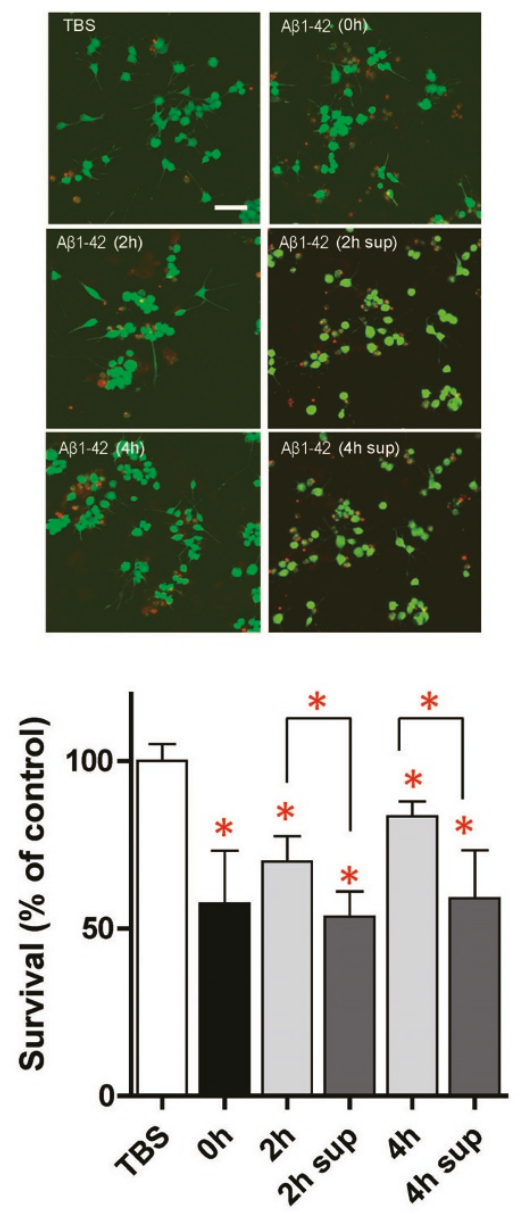

D

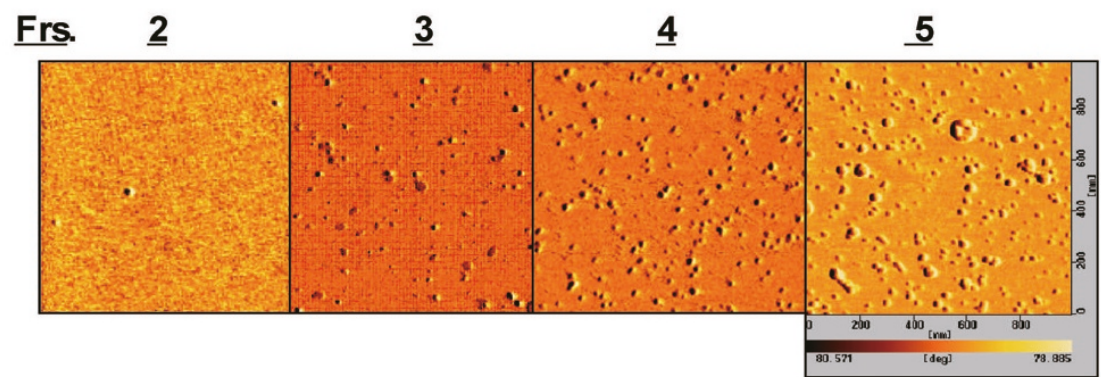

B
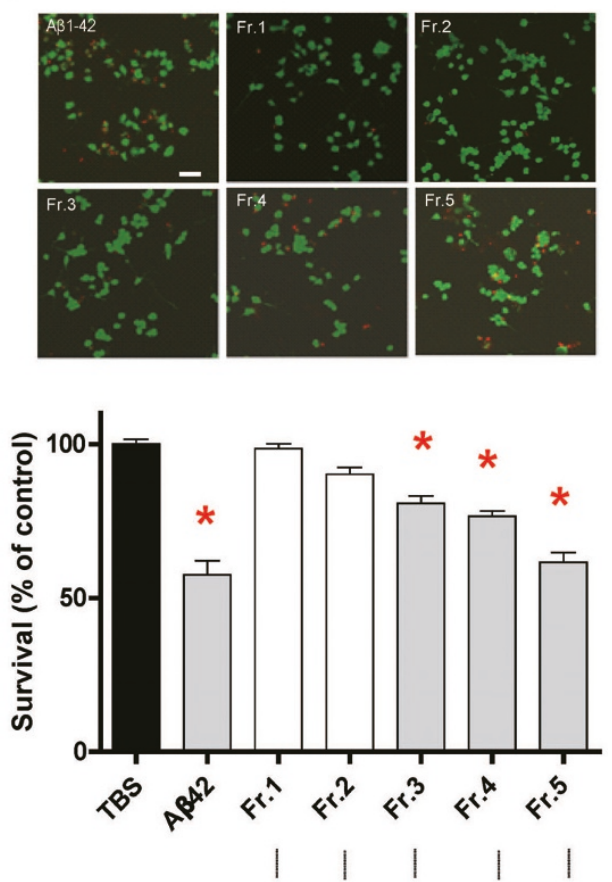

C

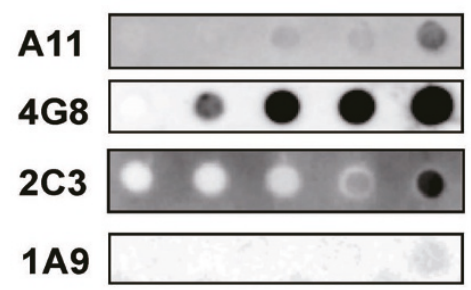

Frs. $1 \quad \underline{2} \quad \underline{3} \quad \underline{4} \quad \underline{5}$

Figure 2 Biophysical and structural characterization of neurotoxic $\mathbf{A} \boldsymbol{\beta}$ assembly. (Upper half of panel $A$ ) Representative calcein $A M / P$

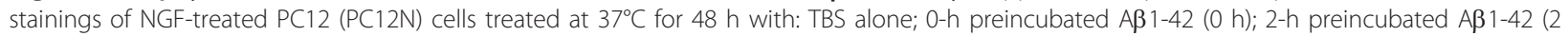
h); 540,000 g supernatant obtained from $2 \mathrm{~h}$ ( $2 \mathrm{~h}$ sup); 4-h preincubated A $1-42$ (4 h); 540,000 g supernatant obtained from $2 \mathrm{~h}$ ( $4 \mathrm{~h}$ sup). Green staining for viable cells versus red staining for dead cells. Resultant cell viability for each treatment is shown in lower half of panel $\mathrm{A}$.

Experimental results were analyzed by one-way ANOVA, followed by Tukey's test for posthoc analysis: statistical significance compared with TBS alone $\left.{ }^{*} p<0.0001\right)$. Scale bar $=50 \mu \mathrm{m}$. (B) The seed-free $A \beta 1-42(25 \mu \mathrm{M})$ was subjected to a series of membrane ultrafiltration steps with molecular cutoffs at 3, 10, 30, and $100 \mathrm{kDa}$. The resultant four filtrates and one retentate were designated as Fr. 1 ( $<3$ kDa), Fr. 2 (3-10 kDa), Fr. 3 (10-30 kDa), and Fr. 4 (30-100 kDa), and final retentate Fr. 5 (>100 kDa). The upper half of panel B shows the representative calcein AM/PI stainings of NGF-treated PC12 (PC12N) cells incubated at $37^{\circ} \mathrm{C}$ for $48 \mathrm{~h}$ with seed-free unfractionated A $1-42$ or five fractions ( $25 \mu \mathrm{M}$ each). Resultant cell viability for each treatment is shown in the lower half of panel B. Experimental results were analyzed by one-way ANOVA, followed by Dannett's test for posthoc analysis: statistical significance compared with TBS alone $\left({ }^{*} p<0.001\right)$. (C) Dot blot analysis of five fractions (Frs. 1-5). The blots were reacted with A11, 1A9, 2C3, and 4G8. (D) Amplitude AFM images ( $2 \mu \mathrm{m} \times 2 \mu \mathrm{m})$ of four fractions (Frs. 2-5). All AFM images were taken on a mica surface. 
seed-free fresh peptide $(0 \mathrm{~h})$ is the best source of de novo formation of neurotoxic $A \beta O$ s. We isolated soluble $A \beta$ species originated from seed-free fresh peptide by ultrafiltration and molecular sieving, which allowed us to separate the toxic $A \beta 42$ peptide into five fractions (Figure $2 \mathrm{~B})$. To verify the size distribution of toxic $\mathrm{A} \beta 42, \mathrm{PC} 12 \mathrm{~N}$ cells were exposed to each fraction $(25 \mu \mathrm{M})$ at $37^{\circ} \mathrm{C}$ for $48 \mathrm{~h}$ (Figure 2B). The level of LDH released from PC12N cells, when treated with each fraction, was similar to that treated with TBS alone. Live/Dead two-color fluorescence assay [22] revealed the toxicity of unfractionated $\mathrm{A} \beta 42$ or Frs. 3-5 (Figure 2B, F $(6 / 77)=39.85, p<$ $0.0001)$, suggesting that toxic oligomers are at least larges trimers. Neurotoxic A $\beta$ Os were then subjected to further dot blot immunoanalysis without SDS to determine their size, in which their "native" conformations are supposed to be maintained (Figure 2C). Monoclonal 4G8 detected A $\beta$ species in Frs. 2-5. The anti-oligomer A11 unequivocally reacted with toxic oligomeric conformers in Frs. 3-5. In contrast, 2C3 immunoreactivities were observed in Frs. 4 and 5, whereas minute amounts of $1 \mathrm{~A} 9$ conformers were detected in toxic Fr. 5 alone. Taken together, these data suggest that both $1 \mathrm{~A} 9$ and $2 \mathrm{C} 3$ toxic conformers are larger than $100 \mathrm{kDa}$ and $30 \mathrm{kDa}$, respectively. Atomic force microscopy (AFM) [25] of toxic fractions revealed structures of different sizes and morphologies, including relatively compact spherical particles approximately 5-10 $\mathrm{nm}$ in diameter, large spherical particles roughly 25-50 $\mathrm{nm}$ in diameter, and an annular pore like structure $25 \mathrm{~nm}$ in inner and $75 \mathrm{~nm}$ in outer diameters (Figure 2D).

\section{$1 \mathrm{~A} 9$ and $2 \mathrm{C} 3$ immunoreactivitiy in human tissue}

To investigate the distribution of 1A9 and 2C3 staining in human tissue, immunohistochemistry was performed on brain tissues obtained from 4 AD and 3 age-matched normal cases. The use of monoclonal 1A9 (Figures 3A and 3I) and, to a lesser extent, monoclonal 2C3 (Figures 3B and 3J) and polyclonal A11 (Figures $3 \mathrm{C}$ and $3 \mathrm{~K}$ ) revealed that $\mathrm{A} \beta \mathrm{Os}$ are highly localized within pyramidal neurons. Within these cells, A $\beta O$ s accumulated as densely packed granules in the perikarya (Figures $3 \mathrm{~A}-\mathrm{C}$ ). Some of the diffuse plaques were stained by $1 \mathrm{~A} 9$, but diffuse deposits were poorly stained by $2 \mathrm{C} 3$ and A11 (Figures $3 \mathrm{~A}-\mathrm{C}$ ). The majority of 1A9-stained pyramidal neurons exhibited atypical, eccentric large nuclei with abnormal chromatin morphology and distributions, features indicative of impending neuronal degeneration (Figures 3A and 3I). Such abnormalities were less evident in 2C3- or A11-stained pyramidal neurons (Figures 3B, C, J and 3K). Although age-matched control brains sometimes contained isolated clusters of $\mathrm{A} \beta \mathrm{O}$-burned neurons (Figures $3 \mathrm{D}$ ), the number of neurons involved and the amount of $\mathrm{A} \beta \mathrm{O}$ s accumulated within these cells were much lower than those in AD brains
(Figures 3D and 3I). Typically, 1A9-immunoreactive granules in control brains were relatively small, numerous, and rather uniformly distributed throughout the perikaryon of pyramidal neurons and the proximal portion of apical dendrites (Figure 3D). In addition, intraneuronal A $\beta$ Os were diffusely distributed throughout the perikaryon of pyramidal neurons, which appears to be a characteristic feature in control brains (Figures 3E and 3I-K). In AD brains, intraneuronal $\mathrm{A} \beta \mathrm{O}$ s were sequestered into large, densely packed aggregates in the dendritic trunk and/or branches, and axons (Figures 3A-C). Interestingly, some showed multiple dot-like accumulation of 1A9-immunoreactive $\mathrm{A} \beta \mathrm{O}$ s arranged in tandem along apical dendritic shafts, which were focally swollen with an accumulation of 1A9immunoreactive $\mathrm{A} \beta \mathrm{O}$ s (Figure $3 \mathrm{~F}$ ). The presence of intraneuronal $A \beta$ was further supported by the staining by the widely used 4G8 (Figure 3G) and 6E10 (Figure 3H).

\section{Extracellular $A \beta O$ s are uptaken by neurons}

To gain further insight into the link between extracellular and intraneuronal $\mathrm{A} \beta \mathrm{Os}$, neuroblastoma (SH-SY5Y) cells were incubated with $5 \mu \mathrm{M}$ HiLyte Fluor ${ }^{\mathrm{TM}} 488$ labeled $\mathrm{A} \beta \mathrm{Ms}$, $\mathrm{A} \beta \mathrm{Os}$, or Fluor ${ }^{\mathrm{TM}} 488$ alone. Immunocytochemical analysis showed that fluorescence-labeled $\mathrm{A} \beta \mathrm{Os}$, not $\mathrm{A} \beta \mathrm{Ms}$, bind to neuronal membrane for $10 \mathrm{~min}$, followed by accumulation of intraneuronal $\mathrm{A} \beta \mathrm{Os}$ for 0.5 or $3 \mathrm{hr}$ (Figure 4A). Vesicular uptake was not observed with fluorescence alone (Figure 4A). Only when Fluor ${ }^{\mathrm{TM}} 488$-labeled A $\beta$ Os were added to SH-SY5Y cells, the LDH release assay [22] of cultures of SH-SY5Y cells revealed that the level of released LDH increased as a function of time (Figure $4 \mathrm{~B}$ ), suggesting that accumulation of intraneuronal $\mathrm{A} \beta \mathrm{O}$ s induces neuronal cell death. The cell death was not detectable in the case of synthetic $A \beta$ 42-1 and $A \beta M$ s (Figure $4 B$ ).

\section{Monoclonal 1 A9 or 2C3 immunotherapy protects Tg2576 from memory impairment}

Using active $1 \mathrm{~A} 9$ and $2 \mathrm{C} 3$ antibodies, we next evaluated whether a specific control of endogenous $\mathrm{A} \beta \mathrm{O}$ s in vivo would be sufficient to prevent the disruption of neuronal function leading to memory loss. To assess this possibility, a long-term low-dose prophylactic study using 1A9 and 2C3 was designed instead of a therapeutic approach that was used previously by other scientists [26,27]. Tg2576 mice were injected with 2 C3 $(n=12), 1 A 9(n=13)$, or PBS $(\mathrm{n}=10)$ into the tail vein $(0.4 \mathrm{mg} / \mathrm{kg} /$ week $)$ from 4 months of age (that is, about 2 months before the onset of memory loss) until 13 months of age (when memory loss and amyloid plaque formation are already well established). Memory functions were measured in four behavioral paradigms, as described previously [28]: (1) short-term memory in the Y-maze test (Figure 5A); (2) object recognition memory in a novel object recognition test (Figure 5B); (3) spatial 


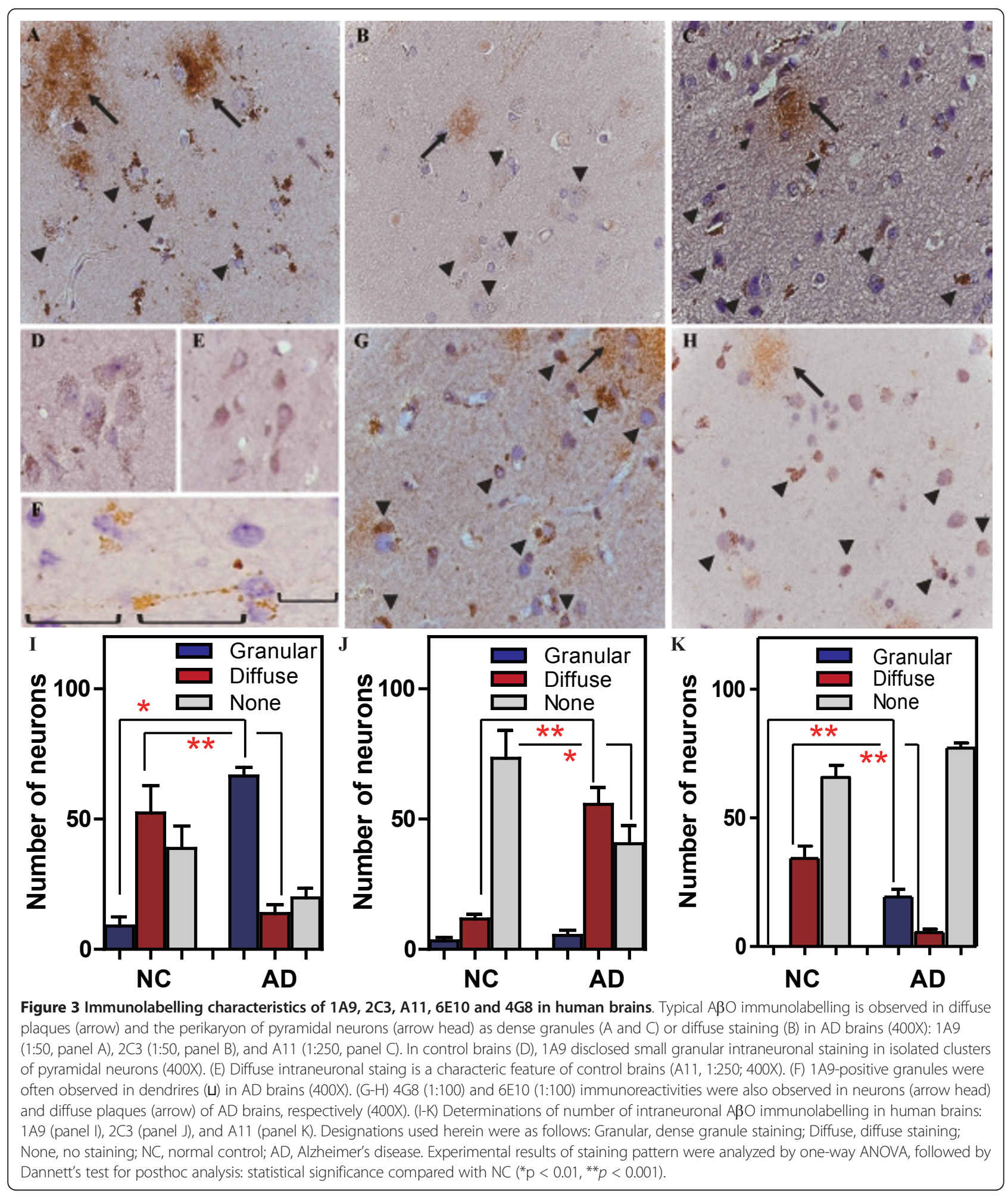

memory in the water maze test (Figures 5C); and (4) associated emotional memory in the contextual fear learning test (Figures 5D and 5E). Untreated Tg2576 mice $(\mathrm{n}=14)$ showed a significantly poorer behavioral performance than untreated wild-type mice in all the behavioral paradigms tested (Figure 5A-5E). Tg2576 mice treated with 1A9 and, to a lesser extent, $2 \mathrm{C} 3$ showed significantly better behavioral performance than untreated Tg2576 mice in all the behavioral paradigms tested (Figures 5A-5E). Unlike that of untreated Tg2576 mice, the performance of 1A9- or 


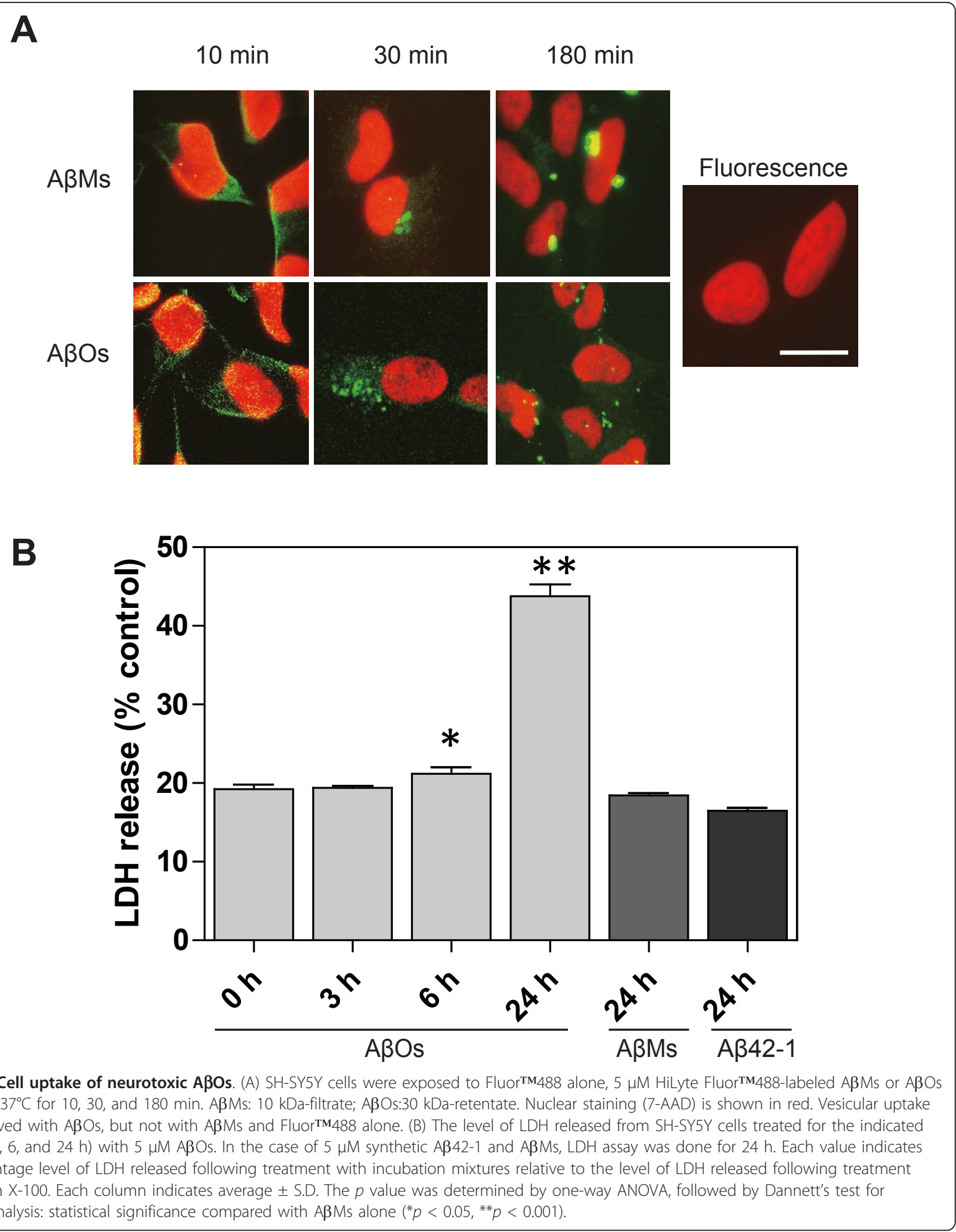

2C3-treated Tg2576 mice was indistinguishable from that of untreated wild-type mice $(\mathrm{n}=14$ ) that had been previously tested in these tasks at this age [28], indicating that both short-term and long-term memories were well preserved in 1A9- or 2C3-treated Tg2576 mice.
Monoclonal 1A9 or 2C3 immunotherapy protects Tg2576 from synaptic degeneration and neuronal degeneration The synaptoprotective effect was also confirmed at the postsynapse level, not at the presynapse level, at which the relative intensities of PSD-95 (Figure 6A) to actin 


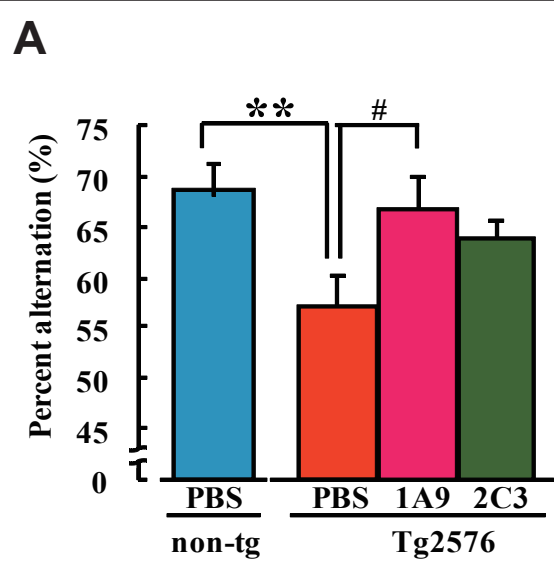

B

C

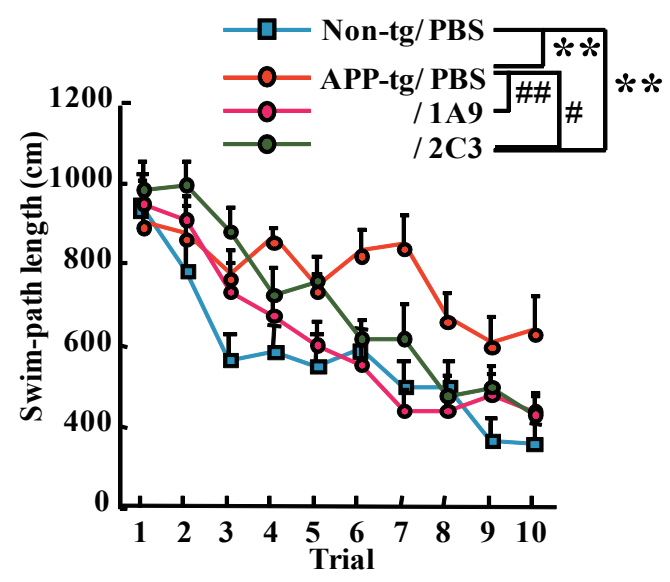

D

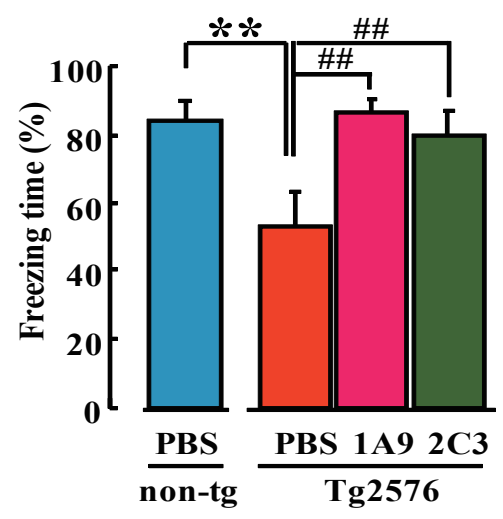

E

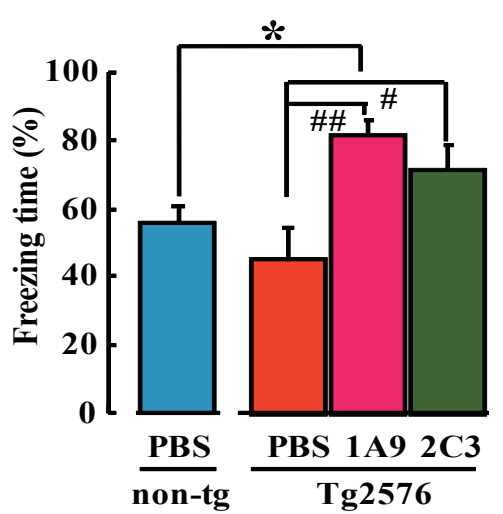

Figure 5 Passive immunization protects Tg2576 mice from memory deficits. Tg2576 mice at 13 months of age in three groups were studied: PBS-treated non-Tg mice, $n=14$; PBS-treated Tg2576 mice, $n=10$; 1A9-treated mice, $n=13$; 2C3-treated mice, $n=12$. Values indicate the mean \pm SEM. (A) Y-maze test. Spontaneous alternation behavior during an 8-min session in the Y-maze task was measured in each group. Results of one-way ANOVA were as follows: $F(3,45)=2.99, p<0.05,{ }^{* *} p<0.05$ vs PBS-treated non-Tg mice, \#p $<0.05$ vs PBS-treated Tg2576 mice. (B) Novel object recognition test. The retention session was carried out $24 \mathrm{~h}$ after the training. Exploratory preference during a 10-min session in the novel-object recognition test was measured in each group. Results of the two-way ANOVA were as follows: training/retention, $\mathrm{F}$ $(1,90)=58.19, p<0.01$; animal group, $F(3,90)=6.18, p<0.01$; interation of training/retention with animal group, $F(3,90)=7.57, p<0.01$; ${ }^{* *} p<0.01$ vs corresponding trained mice. \#\#p $<0.01$ vs PBS-treated non-Tg mice, ${ }^{* *} p<0.01$ vs PBS-treated Tg2576 mice. (C) Swimming-path length during a 60-s session in the water maze test was measured in each group. Results of the two-way ANOVA were as follows: trial, $F(9,450)$ $=25.51, p<0.01$; animal group, $F(3,450)=14.85, p<0.01$; interaction of trial with animal group, $F(27,450)=1.36, p=0.11 ;{ }^{* *} p<0.01$ vs PBS-treated non-Tg mice, \#p $<0.05$, \#\#p $<0.01$ vs PBS-treated Tg2576 mice. Conditioned fear learning test: context-dependent (D) and cuedependent (E) freezing times were measured. The results of one-way ANOVA were as follows: context-dependent test, $F(3,45)=6.19, p<0.01$; cue-dependent test, $\mathrm{F}(3,45)=5.41,{ }^{*} p<0.05$; ${ }^{* *} p<0.01$ vs PBS-treated non-Tg mice, $\# p<0.05, \# \# p 0.01$ vs PBS-treated Tg2576 mice. 
were significantly higher in 2C3-treated Tg2576 mice than in untreated Tg2576 mice. This is not the case with synaptophysin (Figure 6A). Thus, 2C3 indeed protect $\mathrm{Tg} 2576$ mice from postsynaptic degeneration. In addition, the intensities of drebrin (Figure 6A) relative to those of actin were significantly higher in 1A9-treated $\operatorname{Tg} 2576$ mice, indicating that $1 \mathrm{~A} 9$ protects $\mathrm{Tg} 2576$ mice from the degeneration of dendritic spines. This assumption was further supported by image analysis of synaptophysin, PSD-95, or drebrin after immunofluorescence microscopy analysis (Figure 6A).

To further assess the neuroprotective effect of $1 \mathrm{~A} 9$ or 2C3 immunotherapy, Fluoro-Jade B (FJB) binding assay, which specifically detects degenerative neurons, [29], was performed. As depicted in Figure 6B, abundant FJBpositive neurodegenerative neurons were evident in untreated Tg2576 mouse brains. In contrast, such neurodegenerative neurons were negligible in 1A9- (Figure 6B) or 2C3-treated Tg2576 mouse brains (Figure 6B), indicating that $1 \mathrm{~A} 9$ or $2 \mathrm{C} 3$ immunotherapy protects $\mathrm{Tg} 2576$ mice from neuronal degeneration.

Double-labeling analysis of AD brains (Figure 6C) revealed that 1A9- or 2C3-positive neurons were degenerated as proven by Fluoro-Jade $\mathrm{B}(\mathrm{FJB})$ binding, indicating that the accumulation of intraneuronal $A \beta O$ s is closely associated with neuronal degeneration (Figure 6C).

\section{Monoclonal 1 A9 or 2C3 immunotherapy protects Tg2576 from the accumulation of $\mathrm{A} \beta \mathrm{O}$ s}

$\mathrm{w}$ ?> To gain further insight into the neurotoxic action of $\mathrm{A} \beta \mathrm{Os}$, we determined whether $1 \mathrm{~A} 9$ and $2 \mathrm{C} 3 \mathrm{immu}$ notherapies targeting endogenous $\mathrm{A} \beta \mathrm{O}$ s can prevent the accumulation of extracellular or intracellular $A \beta O s$ in vivo. A11-dot immunoblot analysis revealed that 2C3 immunization had a significant preventive effect $(p<0.05$ versus untreated group, post-hoc test) on the level of saline-soluble $\mathrm{A} \beta \mathrm{Os}$ (Figure 7A) which represents extracellular soluble $A \beta O s$. In contrast, $2 \mathrm{C} 3$ and $1 \mathrm{~A} 9$ immunizations resulted in a significant reduction in the level of SDS-extractable $\mathrm{A} \beta \mathrm{O}$ s (Figure 7B), which represents mainly intracellular $A \beta O s$, owing to the specificity of $1 \mathrm{~A} 9$ or $2 \mathrm{C} 3$ towards intracellular $\mathrm{A} \beta$ assembly (see Figure 3). In the case of SDS-insoluble, FA-extractable fractions which represent highly insoluble A $\beta$ Os, A11-dot immunoblot analysis showed that $2 \mathrm{C} 3$ immunization had a significant preventive effect $(p<0.001$ versus untreated group, post-hoc test) (Figure $7 C)$. In accordance with these data, double-labeling analysis revealed that $1 \mathrm{~A} 9$ and $2 \mathrm{C} 3$ immunotherapies prevent the accumulation of A11-immunoreactive granules in the neurons regardless of the abundant A11-specific fluorescence found in untreated mice (Figure 7D).

\section{Discussion}

The development of $\mathrm{A} \beta \mathrm{O}$ s-selective antibodies has greatly facilitated the understanding of in vivo relevance of endogenous $A \beta O s$-mediated synaptic failure or neuronal degeneration. To prove this issue, a prophylactic study to control endogenous $A \beta O$ os using $A \beta O$ Os-selective antibodies is required. Several conformation-dependent antibodies such as oligomer- or fibril-specific antibodies were reported previously $[12,20,21,27,30,31]$, but none of them was examined for this purpose. In the current study, we successfully generated monoclonal oligomer-specific 1A9 and 2C3 using a novel design concept. Monoclonal 1A9 recognizes HMW-oligomers (100 230-mers), whereas $2 \mathrm{C} 3$ recognizes LMW- and HMW-oligomers ranging in sizes larger than pentamers (5 230-mers). In support of a previous report [12], prefibrillar oligomer-selective A11 appears to be specific to HMW-oligomers. Under conditions of SDS-PAGE, 1A9-, 2C3-, or A11-oligomeric conformers were consistently detected at 70-180 kDa corresponding to $15 \sim 40$-mers. Note that neither $1 \mathrm{~A} 9$ nor $2 \mathrm{C} 3$ reacted with monomers and fibrils. In spite of heterogeneity in size, AFM clearly demonstrated that the toxic 1A9-, 2C3-, or A11-oligomeric conformers display relatively compact spherical particles, not fibrilar structure.

Using these oligomer-selective $1 \mathrm{~A} 9$ and $2 \mathrm{C} 3$, we found that the majority of $\mathrm{A} \beta \mathrm{O}$ s exclusively accumulated in neurons, whereas the degree of staining of diffuse plaques varied among antibodies tested $(1 \mathrm{~A} 9>2 \mathrm{C} 3=\mathrm{A} 11)$. Under our conditions tested, A11-immunoreactivity is occasionally found in small diffuse plaques, in contrast with the finding of a previous report [12]. These findings are direct evidence that heterogeneous oligomeric conformers exist as a distinct entity in both extracellular and intraneuronal deposits in human brains. Furthermore, the change of nuclear appearance in $A \beta O$ Os-burned neurons is highly indicative of impending neuronal degeneration: 1A9-positive $\mathrm{A} \beta \mathrm{O}$ s may be associated with the most severe neuronal degeneration among the three anti-oligomer-specific antibodies tested. FJB binding assay, which specifically detects degernerating neurons [29], also confirmed that 1A9- or 2C3-burned neurons in AD brains were unequivocally FJB-positive, indicating that intraneuronal accumulation of $A \beta O$ s is closely associated with neuronal degeneration.

Using above-mentioned $1 \mathrm{~A} 9$ and $2 \mathrm{C} 3$, we evaluated whether a specific control of endogenous, extracellular $\mathrm{A} \beta \mathrm{Os}$ in vivo would be sufficient to prevent the disruption of neuronal function leading to memory loss. Our in vivo investigation demonstrated that immunized subjects have less intraneuronal accumulation of $\mathrm{A} \beta \mathrm{O}$ s and fewer degenerating neurons than untreated controls. In addition, 2C3 and 1A9 protected Tg2576 mice from postsynaptic degeneration and from the degeneration of 
A
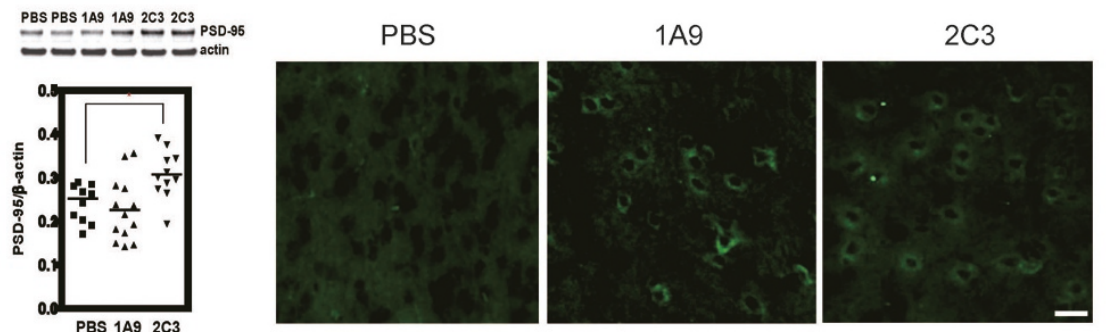

$\begin{array}{llll}\text { PBS PBS } & \text { AA9 } & \text { AA9 } & 2 C 3 \\ 2 C 3\end{array}$

PBS PBS

PBS

$1 \mathrm{~A} 9$

$2 \mathrm{C} 3$
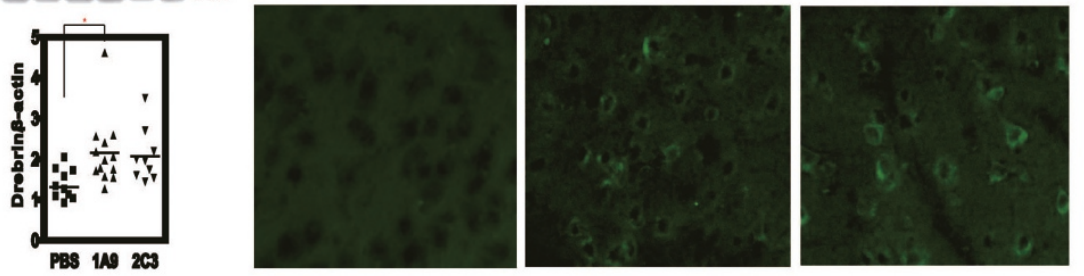

PBS PBS 1 AM 1 A 2 2 CS 2 2C3
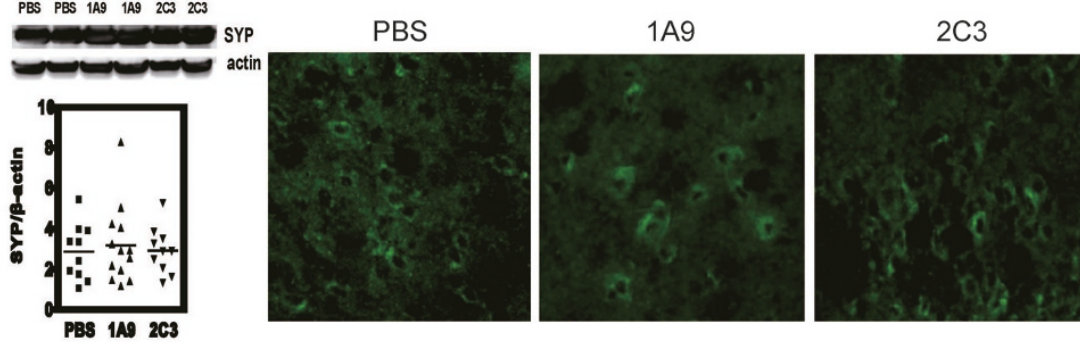

B

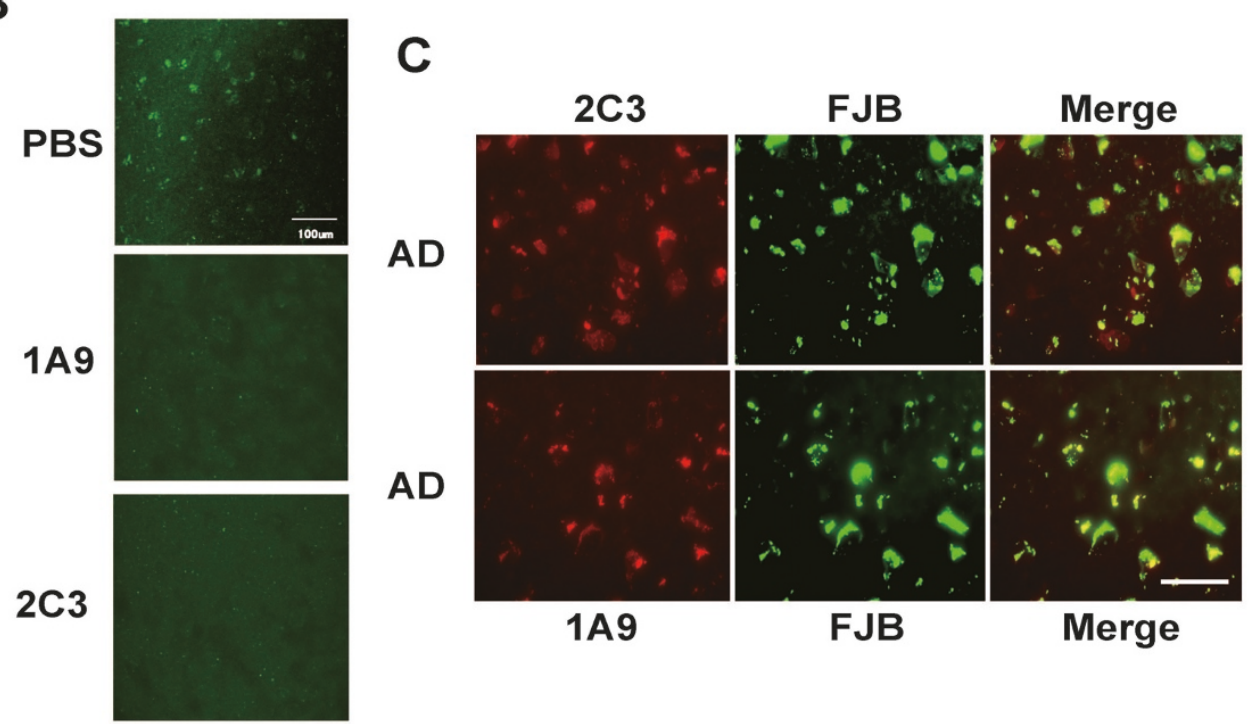

Figure 6 Passive immunization protects Tg2576 mice from synaptic or neuronal degeneration. (A) Saline-insoluble, SDS-extractable synaptic proteins were examined by Western blot analysis and probed for PSD95 (1:250), drebrin (DB, 1:100), and synaptophysin (SYP, 1:2000). The $p$ value was determined by one-way ANOVA: ${ }^{*} p<0.05$. Representive Confocal immunofluorescence microscopy images of Tg2576 mouse brain. Sections of the cortex of the untreated (PBS)-, 1A9-treated, or 2C3-treatedTg2576 mouse brain were immunostained with PSD-95 (Upper part of panel A), Derbrin (DB, Middle part of panel A), synaptophysin (SYP, Lower part of panel A). Scale bar $=30 \mu \mathrm{m}$. (B) Confocal immunofluorescence microscopy images of Tg2576 mouse brain. Sections of the hippocampus of the untreated (PBS)-, 1A9-treated, or 2C3treatedTg2576 mouse brain were immunostained with Fluoro Jade B (1:50000). Scale bar $=100 \mu \mathrm{m}$. (C) Representive Confocal immunofluorescence microscopy images of AD brain. Sections of the hippocampus of AD brains were immunostained with Fluoro Jade B. Scale bar $=20 \mu \mathrm{m}$. 


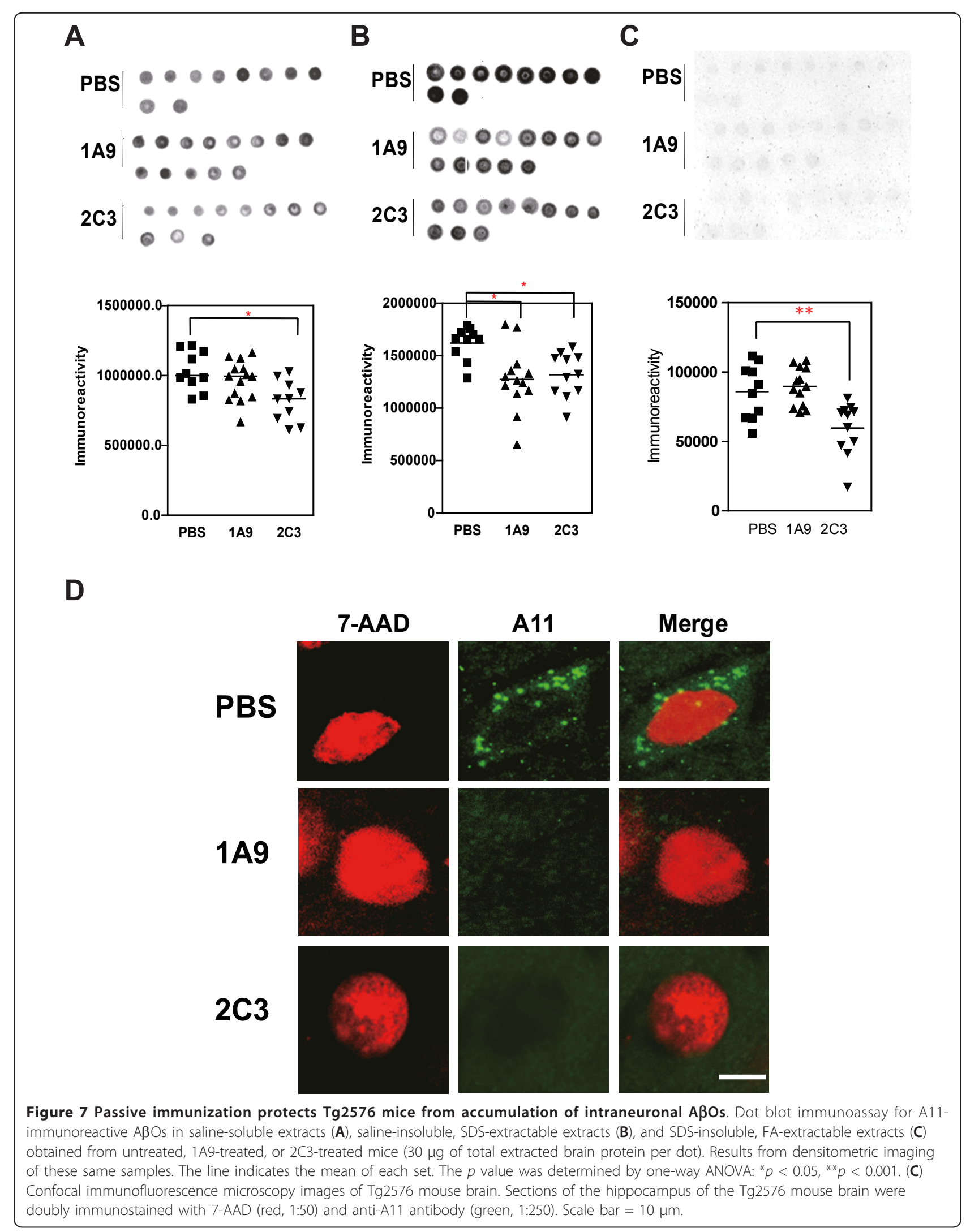


dendritic spines, respectively. These results place both extracellular $[22,32]$ and intraneuronal $\mathrm{A} \beta \mathrm{Os}[33,34]$ centrally within the mechanisms mediating $\mathrm{A} \beta \mathrm{O}$ induced neuronal dysfunction leading to memory loss $[26,27]$. In support of these data, our in vivo investigations clearly demonstrated that $1 \mathrm{~A} 9$ - and 2C3-treated Tg2576 mice aged 13 months showed cognitive performance superior to that of untreated $\operatorname{Tg} 2576$ mice, and, ultimately, performed better than and/or as well as untreated wild-type mice. It is unlikely that the impaired performance of $\operatorname{Tg} 2576$ mice in learning and memory tests is due to changes in motivation or sensory motor function, because the purpose of each behavioral test is different, and different skills are required for a good performance in each test. There were no differences in locomotor activity and the total time spent exploring objects in the novel object test between the wild-type and $\operatorname{Tg} 2576$ mice. Thus, it is likely that endogenous oligomeric $1 \mathrm{~A} 9$ - or $2 \mathrm{C} 3$-conformer is not only generated in Tg2576 mice, but is also actually a bioactive molecule in vivo, and its selective immunoneutralization by systemic administration of $1 \mathrm{~A} 9$ or $2 \mathrm{C} 3$ is sufficient to prevent either short-term or long-term memory loss. This in vivo neuroprotective activity of 1A9 appeared to be superior to that of $2 \mathrm{C} 3$, supporting our current finding that neuronal degeneration in $\mathrm{AD}$ brains is more severe in 1A9-burned neurons than in 2C3-burned neurons. Recently, the generation of a new mouse model expressing only $A \beta O s$ in neurons has demonstrated that endogenous $\mathrm{A} \beta \mathrm{O}$ s are neurotoxic in vivo inducing synaptic alteration, abnormal tau phosphorylation, glial activation, and neuronal loss [35], supporting the pathological relevance of $\mathrm{A} \beta \mathrm{O}$ s as shown herein. Taken together, the results from this study indicate that both extracellular and intraneuronal $\mathrm{A} \beta \mathrm{O}$ s represent a molecular basis of memory loss in vivo. Additional studies that attempt to identify the cellular and molecular targets on the cellular surface with which $1 \mathrm{~A} 9$ or $2 \mathrm{C} 3$ interacts may yield insights into the mechanisms underlying the synaptotoxic or neurotoxic effects of $\mathrm{A} \beta \mathrm{O}$ s or synaptoprotective or neuroprotective effect of $1 \mathrm{~A} 9$ or $2 \mathrm{C} 3$.

\section{Conclusions}

We herein performed a hypothesis-driven, proof of concept study to prove the relevance of the in vivo $\mathrm{A} \beta$ oligomer hypothesis using monoclonal antibodies specific to $A \beta O$ s generated using a novel design method. We found that $\mathrm{A} \beta \mathrm{O}$ s are not only the real memory-relevant molecules, but also the real culprits of neuronal degeneration. Now, we have evidence that $A \beta O$ s are among the earliest manifestation of the $\mathrm{AD}$ toxic process in mice and humans. We are certain that our studies move us closer to our goal of finding a therapeutic target and/ or confirming the relevance of our therapeutic strategy.

\section{Methods}

\section{Generation of monoclonal $1 \mathrm{~A} 9$ and $2 \mathrm{C3}$}

Synthetic A $\beta 1-42$ (r-peptide, Osaka, Japan) was dissolved in distilled, deionized $\mathrm{H}_{2} \mathrm{O}$, or $10 \mathrm{mM}$ phosphate buffer at $250 \mu \mathrm{M}$, and allowed to incubate at $37^{\circ} \mathrm{C}$ for $18 \mathrm{~h}$. Twenty microgram of preincubated $A \beta 1-42$ was separated by NuPAGE 4-12\% Bis-tris glycine gels, followed by CBB staining. Balb-c mice were immunized by injection with $2.5 \mu \mathrm{g}$ of $\mathrm{A} \beta 1-42$ tetramer alone, which was excised from the gel and emulsified with complete Freund's adjuvant, into foot pads, followed by six additional injections. Inguinal lymphonode was used to generate hybridomas by fusion with $\mathrm{Sp} 2 / \mathrm{O}-\mathrm{Ag} 14$ myeloma cells with polyethylene glycol 1500 . Initial screening was performed by dot blot analysis, applying $2.5 \mu \mathrm{l}$ of seedfree fresh or 18-h preincubated A $1-42(2.5 \mathrm{ng} / \mathrm{dot})$ to a nitrocellulose membrane [22]. The blots were then allowed to dry and blocked with 5\% low-fat milk and $1 \%$ BSA in PBS containing 0.05\% Tween-20 (PBST) and incubated with culture medium supernatant, followed by horseradish peroxidase (HRP)-labeled goat anti-mouse or anti-rabbit $\mathrm{F}\left(\mathrm{ab}^{\prime}\right)_{2}$ antibody (1:3000; Amersham). Dot immunoblots were visualized with an ECL kit using LAS3000 mini (Fujitsu, Tokyo, Japan).

\section{Preparation of $A \beta 1-42$ peptide}

Synthetic A $\beta 1-42$ was dissolved in $0.02 \%$ ammonia solution at $250 \mu \mathrm{M}$. To obtain seed-free $\mathrm{A} \beta 42$ solutions (540,000 g sup), the prepared solutions were centrifuged at $540,000 \mathrm{~g}$ for $3 \mathrm{~h}$ using an Optima TL ultracentrifuge (Beckman, USA) to remove undissolved peptides, which can act as preexisting seeds. The supernatant was collected and stored in aliquots at $-80^{\circ} \mathrm{C}$ until use. Immediately before use, the aliquots were thawed and diluted with TBS (150 mM NaCl and $10 \mathrm{mM}$ Tris- $\mathrm{HCl}, \mathrm{pH}$ 7.4). For timecourse experiments, 540,000 g sup was incubated for an indicated time (0-72 h), and soluble $A \beta O$ s were retained after 100,000 g ultracentrifugation for $1 \mathrm{~h}$, followed by dot immunoblot analysis (2.5 ng/dot) [22]. Because the 4-hincubated mixture is suitable for the characterization of soluble $\mathrm{A} \beta \mathrm{O}$ standards, we used it in further experiment instead of the 18-h-incubated mixture used in the first screening. To further assess whether monoclonal 1A9 or $2 C 3$ recognizes $A \beta$ fibrils, seed-free $A \beta 42$ solutions (25 $\mu \mathrm{M})$ were incubated for 5 days at room temperature. Electron-microscopy-confirmed $A \beta$ fibrils were subjected to dot immunoblot analysis (2.5 ng/dot) [22].

\section{Electron microscopy (EM)}

For electron microscopy, samples were diluted with distilled water and spread on carbon-coated grids. The grids were negatively stained with $1 \%$ phosphotungstic acid and examined under a Hitachi H-7000 electron microscope (Tokyo, Japan) with an acceleration voltage of $77 \mathrm{kV}$. 


\section{BN-PAGE and two-dimensional Natie/SDS-PAGE}

BN-PAGE analysis was performed following the manufacture's instruction (Invitrogen, Carlsbad, CA): 4\%, 6\%, $8 \%, 10 \%, 12 \%, 14 \%, 16 \%, 18 \%, 20 \%$, and $4-16 \%$ Novex $^{\circledR}$ Bis-Tris gel was used. The apparent molecular masses of LMW-oligomers were calculated from the Ferguson plots with known molecular mass standards ( $\alpha$-lactalbumin, $14.2 \mathrm{kDa}$; carbonic anhydrase, $29 \mathrm{kDa}$; chickin egg albumin, $45 \mathrm{kDa}$; bovine serum albumin, $66 \mathrm{kDa}$ monomer, and $132 \mathrm{kDa}$ dimer; urease, $272 \mathrm{kDa}$ monomer and $545 \mathrm{kDa}$ dimer) (Sigma). For two-dimensional native/ SDS-PAGE, one lane was excised from the gel and applied directly for SDS-PAGE. Immunoblot analysis was performed as described previously [36].

\section{$A \beta$-induced toxicity assay}

We conducted the $A \beta$-induced toxicity assay according to previously published methods [22]. Briefly, rat pheochromocytoma 12 (PC12) cells were cultured in DMEM (Invitrogen, Carlsbad, CA) supplemented with 10\% heatinactivated horse serum (Invitrogen) and 5\% FBS (Invitrogen). For their differentiation, PC12 cells were plated on $10-\mathrm{cm}^{2}$ poly-L-lysine-coated $(10 \mathrm{mg} / \mathrm{ml})$ dishes at a density of 20,000 cells $/ \mathrm{cm}^{2}$ and cultured for 6 days in DMEM supplemented with $100 \mathrm{ng} / \mathrm{ml}$ nerve growth factor (NGF; Alomone Labs, Jerusalem, Israel) (PC12N). Basically, toxicity was assessed using different $A \beta$ conformers: seed-free $A \beta 1-42$ vs. 2-h- or 4-h-preincubated A $\beta$ 1-42 with or without 540,000 g ultracentrifugation for $1 \mathrm{~h}$. PC12N was exposed to seed-free or preincubated $\mathrm{A} \beta 1-42$ at $25 \mu \mathrm{M}$ for $48 \mathrm{~h}$ at $4^{\circ} \mathrm{C}$. Toxicity was assessed by Live/Dead two-color fluorescence assay (Molecular Probes, Eugene, OR) or CytoTox 96 NonRadioactive Cytotoxicity Assay Kit (Promega, Madison, DI) in accordance with the manufacturer's instructions as described previously [22].

\section{Ultrafiltration and molecular sieving (UF/MS)}

To characterize the size of de novo formed toxic A $\beta \mathrm{Os}$ at $25 \mu \mathrm{M}$, serial ultrafiltration using Microcon ${ }^{\circledR} 3-$, 10-, 30-, and 10-kDa cut-off membranes (Millipore Corp. Billerica, MA) was performed to prepare four filtrates (12,000 g-centrifuge for $90 \mathrm{~min}, \mathrm{Fr} .1$, >3 kDa; 12,000 gcentrifuge for $60 \mathrm{~min}$, Fr. 2, 3-10 kDa; 12,000 g-centrifuge for $30 \mathrm{~min}$, Fr. 3, 10-30 kDa; 12,000 g-centrifuge for $15 \mathrm{~min}$, Fr. 4, 30-100 kDa) and one retentate (Fr. 5, $>100 \mathrm{kDa}$ ). Each fraction at $25 \mu \mathrm{M}$ was subjected to $\mathrm{A} \beta$ induced toxicity assay as described above. PC12N cells were exposed to each fraction and the toxic fraction was assessed as described above. The distribution of the A11, 1A9, 2C3, or 4G8 conformer was characterized by dot blot analysis as described above. To determine the morphology of toxic oligomers, each fraction was also subjected to atomic force microscopy (AFM).

\section{Atomic force microscopy (AFM)}

AFM assessment was performed as reported previously [25]. Briefly, samples were dropped onto freshly cleaved mica. After allowing them to stand for $1 \mathrm{~h}$, following by washing with water, the samples were assessed in a solution using a Nanoscope IIIa (Digital Instruments, Santa Barbara, CA, USA) set at tapping mode. OMCLTR400PSA (Olympus, Japan) was used as a cantilever. Consecutive scans were monitored until distortion due to creep or shifts in the slow scan direction were negligible before collecting scans at sizes of $2 \mu \mathrm{m}$ with the maximum $512 \times 512$ pixel resolution .

\section{Immunohistochemistry}

The left hemispheres of the brains of Tg2576 mice were sagitally cut into $30-\mu \mathrm{m}$-thick sections using a freezing microtome (RM 2145; Leika, Wetzlar, Germany). The tissue blocks from human subjects (4 AD subjects and 3 normal controls) or mice were fixed in $4 \%$ paraformaldehyde with $0.1 \mathrm{M}$ phosphate-buffered saline ( $\mathrm{pH}$ 7.6) and embedded in paraffin wax. After deparaffinization, heat-induced antigen retrieval was achieved by boiling sections for $10 \mathrm{~min}$ in a microwave oven in $0.01 \mathrm{M}$ citrate buffer pH6.0, followed by 3 min incubation in 99\% formic acid and then blocking of endogenous peroxidase. Then sections were subsequently incubated for 1 hour with primary antibody diluted in blocking buffer with normal goat or horse serum (2\%), and after washing for 1 hour, with a secondary antibody in the same buffer. All incubations were done in parallel and photograph exposures were equal for sections in human and mice.

The following primary antibodies were used: monoclonal antibodies $6 \mathrm{E} 10$ and 4G8 against human $\mathrm{A} \beta$ sequence corresponding to residues 1-16 and 17-24, respectively, (Covance Immuno-Technologies, Dedham, MA), Polyclonal A11 specific to A $\beta$ Os (Biosource, Camarillo, CA), anti-SYP (D4) antibody, monoclonal antibody against $\beta$-actin (C4) (Santa Cruz, Santa Cruz, CA), monoclonal anti-drebrin antibody (MBL, Nagoya, Japan), polyclonal anti-PSD-95 (CT) antibody (Invitrogen, Camarillo, CA), and our monoclonal 1A9 and 2C3 antibodies specific to $\mathrm{A} \beta \mathrm{Os}$.

The following secondary antibodies were used (1:1000): Goat anti-rabbit or anti-mouse IgG conjugated with horse-radish peroxidase (HRP) (Invitorogen, Carlsbad, CA), and Goat anti-mouse IgG conjugated with Alex Fluor (AF) 488 or 594 and goat anti-rat IgG conjugated with AF 488 (Molecular Probes, Eugene, OR). Immunopositive signals were visualized using an observation system (Compix Imaging System, Lake Oswego, OR) linked to an Olympus microscope BX50 through a highly sensitive CCD camera or a confocal laser scanning microscope (Carl Zeiss LSM510). 
Fluoro-Jade B was purchased from Chemicon (now part of Millipore, Schwalbach, Germany). 7-AAD was purchased from Invitrogen (Carlsbad, CA).

\section{Histochemistry}

For Fluoro-Jade B histochemistry (1:50000), 5- $\mu \mathrm{m}$-thick paraffin-embedded sections were deparafinized and stained following the manufacturer's instruction (Chemicon, now part of Millipore, Schwalbach, Germany). The Fluoro-Jade B-stained product fluoresces when exited at $488 \mathrm{~nm}$ and staining was imaged using a confocal laser scanning microscope (Carl Zeiss LSM510). The same procedure was applied for $30-\mu \mathrm{m}$-thick cryostat sections.

\section{Cell culture and cellular uptake}

Human neuroblastoma SH-SY5Y (SY5Y) cells were cultured in Dulbecco's modified Eagle's medium/Ham's F-12 medium supplemented with $10 \%$ fetal bovine serum. To investigate the fate of extracellular $A \beta, S Y 5 Y$ cells were exposed to HiLyte Fluor ${ }^{\mathrm{TM}} 488$-labeled A $\beta \mathrm{Ms}(10 \mathrm{kDa}-$ filtrate), HiLyte Fluor ${ }^{\mathrm{TM}} 488$-labeled $\mathrm{A} \beta \mathrm{Os}$ (30 kDaretentate) at $5 \mu \mathrm{M}$ (AnaSpec, San Jose, CA), or Fluor ${ }^{\mathrm{TM}} 488$ alone for $10 \mathrm{~min}, 30 \mathrm{~min}$, and $180 \mathrm{~min}$. In a separate set of experiment, cultures were treated at $37^{\circ} \mathrm{C}$ for $0,3,6$, and $24 \mathrm{~h}$ with $5 \mu \mathrm{M}$ Fluor ${ }^{\mathrm{TM}} 488$-labeled $\mathrm{A} \beta \mathrm{Os}$, and for $24 \mathrm{~h}$ with $5 \mu \mathrm{M}$ Fluor ${ }^{\mathrm{TM}} 488$-labeled $\mathrm{A} \beta \mathrm{Ms}$ and synthetic $\mathrm{A} \beta 42-$ 1 (AnaSpec, San Jose, CA). Toxicity was assessed by CytoTox 96 Non-Radioactive Cytotoxicity Assay Kit in accordance with the manufacturer's instructions (Promega, Madison, DI) as described previously [22].

\section{Protein extraction and immunoblotting}

Saline-soluble, saline-insoluble, SDS-soluble fractions, or SDS-insoluble, formic acid (FA)-extractable fractions were prepared from the Tg2576 mouse brains as described previously [32]. Briefly, frozen brain samples were homogenized with a motor-driven Teflon/glass homogenizer (20 strokes) in TBS containing a cocktail of protease inhibitors $(150 \mathrm{mg} / \mathrm{ml})$, followed by centrifugation at 100,000 $g$ for $1 \mathrm{~h}$. The resultant supernatant (soluble fraction) was subjected to dot blot immunoanalysis or western blotting employing the same antibodies as those used for immunohistochemical staining. The pellet was further extracted with $2 \%$ sodium dodecylsulphate (SDS), followed by $70 \%$ FA, and the homogenate was ultracentrifuged as described above. The resultant supernatant (insoluble fraction) was also subjected to dot blot immunoanalysis and western blot analysis. For western blotting, aliquots of isolated fractions were separated using NuPAGE 4-12\% bis-tris-glycine gels and transblotted to nitrocellulose membrane or Immobilon P (Millipore) for $1 \mathrm{~h}$ at $400 \mathrm{~mA}$ using $10 \mathrm{mM}$ 3-cyclohexylamino-1-propancsulphonic acid (pH 11) containing 10\% methanol. Membranes were blocked for $3 \mathrm{~h}$ at room temperature with $5 \%$ low-fat milk and $1 \%$ BSA in
PBST and incubated with either the polyclonal anti-A11 (1:1000) or anti-PSD95 antibody (1:250), and monoclonal anti-drebrin (1:100), anti-SYP (1:2000), and anti- $\beta$ actin antibodies (1:1000), followed by HRP-labeled goat antirabbit or anti-mouse $\mathrm{F}\left(\mathrm{ab}^{\prime}\right)_{2}$ antibody (1:3000; Amersham). Immunoblots were visualized with an ECL kit using LAS3000 mini (Fujitsu, Tokyo, Japan). Densitometric analysis of immunoblot was performed using Multi Gauge v3.0 software (Fuji Film, Tokyo), and bands of interest were normalized to the corresponding actin bands indicated.

\section{Immunization and behavioral analyses}

All animal procedures were performed in accordance with a protocol approved by the Animal Care Committee of the National Institute for Longevity Sciences. Several 3-month-old female nontransgenic (non-Tg) and Tg2576 mice that carry and overexpress the human APP gene with the Swedish double mutation (K670N; M671L) of familial AD were purchased from Taconics (Germantown, NY, USA) and maintained at our animal care facility until 13 months of age. To determine whether immunization prevents the development of Alzheimer-like phenotype, 4-month-old Tg2576 mice were administered 1A9 or 2C3 $(0.4 \mathrm{mg} / \mathrm{kg} /$ week $)$, or PBS intravenously via the tail vein until 13 months of age. Memory functions were measured at 13 months of age in the following four behavioral paradigms, as described previously [28]: (1) spontaneous alternation in the Y-maze test; (2) novel object recognition test; (3) Morris water maze test; and (4) cued and fear conditioning tests. Mice were sacrificed 3 days after the termination of the behavioral tests for biochemical and histological assessments. Experimental results were analyzed by one-way ANOVA and two-way ANOVA, with Fisher's test for post hoc analysis.

\section{Spontaneous alternation in Y-maze test}

The maze was made of black painted wood; each arm was $40 \mathrm{~cm}$ long, $12 \mathrm{~cm}$ high, $3 \mathrm{~cm}$ wide at the bottom, and $10 \mathrm{~cm}$ wide at the top. The arms converged at an equilateral triangular central area that was $4 \mathrm{~cm}$ long at its longest axis. Each mouse was placed at the center of the apparatus, the sequence and number of arm entries were recorded for each mouse over an 8 min period. Alternation was defined as successive entry into the three arms on overlapping triplet sets. Alternation behavior (\%) was calculated as the ratio of actual alternations to possible alternations (defined as the number of arm entries minus two) multiplied by 100 .

\section{Novel object recognition test}

The test procedure consisted of three sessions: habituation, training, and retention. Each mouse was habituated to the box $(30 \times 30 \times 35 \mathrm{~cm})$, with 10 min of exploration 
in the absence of objects for 3 days (habituation session). During the training session, two objects were placed at the back corner of the box. A mouse was then placed midway at the front of the box and the total time spent exploring the two objects was recorded for $10 \mathrm{~min}$. During the retention session, the mice were placed back in the same box $24 \mathrm{hr}$ after the training session, in which one of the familiar objects used during the training was replaced with a novel object. The animals were then allowed to explore freely for $10 \mathrm{~min}$, and the time spent exploring each object was recorded. Throughout the experiments, the objects used were counterbalanced in terms of their physical complexity and emotional neutrality. A preference index, a ratio of the amount of time spent exploring any one of the two objects (training session) or the novel object (retention session) over the total time spent exploring both objects, was used to measure cognitive function. To eliminate the influence of the last behavioral test, the objects were changed each time.

\section{Morris water maze test}

The Morris water maze test was conducted in a circular pool (120 cm in diameter) filled with water at a temperature of $22 \pm 1^{\circ} \mathrm{C}$. A hidden platform (one block) (7 cm in diameter) was used. The mice underwent two trials (one block) for 10 consecutive days, during which the platform was left in the same position. The distance taken to locate the escape platform was determined in each trial using the Etho Vision system (Neuroscience Idea Co., Ltd., Osaka, Japan).

\section{Cued and contextual fear conditioning tests}

For measuring basal levels of freezing response (preconditioning phase), mice were individually placed in the conditioning cage $(17 \times 27 \times 12.5 \mathrm{~cm})$ for $1 \mathrm{~min}$, then in the conditioning cage $(25 \times 31 \times 11 \mathrm{~cm})$ for $2 \mathrm{~min}$. For training (conditioning phase), mice were placed in the conditioning cage, then a $15 \mathrm{sec}$ tone $(80 \mathrm{~dB})$ was delivered as a conditioned stimulus. During the last $5 \mathrm{sec}$, an unconditioned stimulus was applied through a shock generator (Neuroscience Idea Co., Ltd.). This procedure was repeated 4 times at 15 sec intervals. Cued and contextual tests were carried out 1 day after the fear conditioning. For the cued test, the freezing response was measured in the neutral cage for $1 \mathrm{~min}$ in the presence of a continuous-tone stimulus identical to the conditioned stimulus. For the contextual test, mice were placed in the conditioning cage and the freezing response was measured for $2 \mathrm{~min}$ in the absence of the conditioned stimulus.

\section{Ethics Statement}

The research protocol was approved by the local animal esthetics committees at Research Institute, National
Center for Geriatrics and Gerontology (Animal Care Committee) prior to initiation of the study. The research project was approved by the local ethics committee of Hirosaki University Graduate School of Medicine, and Research Institute, National Center for Geriatrics and Gerontology prior to initiation of the study.

\section{Statistical analyses}

We used factorial design analysis of variaence (ANOVA) or Mann-Whitney test to analyze data as appropriate. Significant ANOVA values were subsequently subjected to simple main effects analyses or post hoc comparisons of individual means using the Tukey's or Dannett's method as appropriate. We considered $p$ values of 0.05 as significant for all studies. Some of the data obtained from animal experiments were analyzed by two-way ANOVA, with Fisher's test for post hoc analysis.

\section{Acknowledgements}

This work was supported in part by a Grant-in-Aid for Advanced Brain Scientific Project-from the Ministry of Education, Culture, Sports, Science and Technology, Japan [15016080 and 16015284 to E.M.]; and the Research Grant for Longevity Sciences from the Ministry of Health, Labour and Welfare [17A1 to E.M.].

\section{Author details}

${ }^{1}$ Department of Alzheimer's Disease Research, Research Institute, National Center for Geriatrics and Gerontology, Aichi, Japan. ${ }^{2}$ Department of Neurology, Institute of Brain Science, Hirosaki University Graduate School of Medicine, Aomori, Japan. ${ }^{3}$ Immunas Pharma Incorporation, Kanagawa, Japan. ${ }^{4}$ Department of Chemical Pharmacology, Graduate School of Pharmaceutical Sciences, Meijo University, Aichi, Japan. ${ }^{5}$ Department of Neurology, Okayama University School of Medicine, Okayama, Japan. ${ }^{6}$ Department of Life and Coordination-Complex Molecular Science, Institute for Molecular Science, Aichi, Japan.

\section{Authors' contributions}

Conceived and designed the experiments: MM EM. Performed the experiments: AT YO TK AM TN HS TU NY EM. Analyzed the data: MS MS KY MM. Contributed reagents/materisals/analysis tools: YO TY MS KA. Wrote the paper: AT EM. All authors read and approved the final manuscript.

\section{Competing interests}

YO, TY, and MS are the employees in Immunas Pharma Incorporation. TY and MS hold stock options in Immunas Pharma Incorporation. EM, TY, and MS are co-inventors of two filed provisional patent applications titled "Antibody Specific Binding to a Beta Oligomer and The Use" and "Antibodies That Specifically Bind to A $\beta$ Oligomers and Uses Thereof" that cover the antibodies described in this paper, but this does not alter the adherence to all the Molecular Neurodegeneration policies on sharing data and materials. This study has in some parts been funded by a commercial funder, but that does not alter the author's adherence to all the Molecular

Neurodegeneration policies on sharing data and materials.

Received: 13 August 2010 Accepted: 6 March 2011

Published: 6 March 2011

\section{References}

1. Hardy J, Allsop D: Amyloid deposition as the central event in the aetiology of Alzheimer's disease. Trends Pharmacol Sci 1991, 12:383-388.

2. Lue LF, Kuo YM, Roher AE, Brachova L, Shen Y, Sue L, Beach T, Kurth JH, Rydel RE, Rogers J: Soluble amyloid $\beta$ peptide concentration as a predictor of synaptic change in Alzheimer's disease. Am J Pathol 1999, 155:853-862. 
3. McLean CA, Cherny RA, Fraser FW, Fuller SJ, Smith MJ, Beyreuther K, Bush Al, Masters CL: Soluble pool of Abeta amyloid as a determinant of severity of neurodegeneration in Alzheimer's disease. Ann Neurol 1999, 46:860-866.

4. Klein WL, Krafft GA, Finch CE: Targeting small Abeta oligomers: the solution to an Alzheimer's disease conundrum? Trends Neurosci 2001, 24:219-224.

5. Selkoe DJ: Alzheimer's disease is a synaptic failure. Science 2002, 298:789-791.

6. Hass C, Selkoe DJ: Soluble protein oligomers in neurodegeneration: lessons from the Alzheimer's amyloid $\beta$-peptide. Nat Rev Mol Cell Biol 2007, 8:101-112.

7. Akiyama H, Barger S, Barnum S, Bradt B, Bauer J, Cole GM, Cooper NR, Eikelenboom P, Emmerling M, Fiebich BL, Finch CE, Frautschy S, Griffin WS Hampel H, Hull M, Landreth G, Lue L, Mrak R, Mackenzie IR, McGeer PL, O'Banion MK, Pachter J, Pasinetti G, Plata-Salaman C, Rogers J, Rydel R, Shen Y, Streit W, Strohmeyer R, Tooyoma I, Van Muiswinkel FL, Veerhuis R, Walker D, Webster S, Wegrzyniak B, Wenk G, Wyss-Coray T: Inflammation and Alzheimer's disease. Neurobiol Aging 2000, 21:383-421.

8. Hardy JA, Higgins GA: Alzheimer's disease: the amyloid cascade hypothesis. Science 1992, 256:184-185.

9. Lambert MP, Barlow AK, Chromy BA, Edwards C, Freed R, Liosatos M, Morgan TE, Rozovsky I, Trommer B, Viola KL, Wals P, Zhang C, Finch CE: Diffusible, nonfibrillar ligands derived from $A \beta_{1-42}$ are potent central nervous system neurotoxins. Proc Natl Acad Sci USA 1998, 95:6448-6453.

10. Dodart JC, Bales KR, Gannon KS, Greene SJ, DeMattos RB, Mathis C, DeLong CA, Wu S, Wu X, Holtzman DM, Paul SM: Immunization reverses memory deficits without reducing brain $A \beta$ burden in Alzheimer's disease model. Nat Neurosci 2002, 5:452-457.

11. Chromy BA, Nowak RJ, Lambert MP, Viola KL, Chang L, Velasco PT, Jones BW, Fernandez SJ, Lacor PN, Horowitz P, Finch CE, Krafft GA, Klein WL: Self-assembly of $A \beta_{1-42}$ into globular neurotoxins. Biochemistry 2003, 42:12749-12760.

12. Kayed R, Head E, Thompson JL, Mclntire TM, Milton SC, Cotman CW, Glabe CG: Common structure of soluble amyloid oligomers implies common mechanism of pathogenesis. Science 2003, 300:486-489.

13. Bayer A, Jones RW, Bullock R, Love S, Neal JW, Zotova E, Nicoll JA: Longterm effects of Abeta42 immunisation in Alzheimer's disease: follow-up of a randomised, placebo-controlled phase I trial. Lancet 2008, 372:216-223.

14. Walsh DM, Klyubin I, Fadeeva JV, Cullen WK, Anwyl R, Wolfe MS, Rowan MJ, Selkoe DJ: Naturally secreted oligomers of amyloid $\beta$ protein potently inhibit hippocampal long-term potentiation in vivo. Nature 2002, 16:535-539.

15. Shankar GM, Li S, Mehta TH, Garcia-Munoz A, Shepardson NE, Smith I, Brett FM, Farrell MA, Rowan MJ, Lemere CA, Walsh DM, Sabatini BL, Selkoe DJ: Amyloid-betaprotein dimers isolated directly from Alzheimer's brains impairsynaptic plasticity and memory. Nat Med 2008, 14:837-842.

16. Lacor PN, Buniel MC, Chang L, Fernandez SJ, Gong Y, Viola KL, Lambert MP, Velasco PT, Bigio EH, Finch CE, Krafft GA, Klein WL: Synaptic targeting by Alzheimer's-related amyloid $\beta$ oligomers. J Neurosci 2004, 24:10191-10200.

17. Cleary JP, Walsh DM, Hofmeister JJ, Shankar GM, Kuskowski MA, Selkoe DJ, Ashe $\mathrm{KH}$ : Natural oligomers of the amyloid- $\beta$ protein specifically disrupt cognitive function. Nat Neurosci 2005, 8:79-84.

18. Lesné S, Koh MT, Kotilinek L, Kayed R, Glabe CG, Yang A, Gallagher M, Ashe $\mathrm{KH}$ : A specific amyloid-beta protein assembly in the brain impairs memory. Nature 2006, 440:352-357.

19. Gong Y, Chang L, Viola KL, Lacor PN, Lambert MP, Finch CE, Krafft GA Klein WL: Alzheimer's disease-affected brain: presence of oligomeric $A \beta$ ligands (ADDLs) suggests a molecular basis for reversible memory loss. Proc Natl Acad Sci USA 2003, 100:10417-10422.

20. O'Nuallain B, Wetzel R: Conformational Abs recognizing a generic amyloid fibril epitope. Proc Natl Acad Sci USA 2002, 99:1485-1490.

21. Kayed R, Head E, Sarsoza F, Saing T, Cotman CW, Necula M, Margol L, Wu J, Breydo L, Thompson JL, Rasool S, Gurlo T, Butler P, Glabe CG: Fibril specific, conformation dependent antibodies recognize a generic epitope common to amyloid fibrils and fibrillar oligomers that is absent in prefibrillar oligomers. Mol Neurodeg 2007, 2:18-28.

22. Yamamoto N, Matsubara E, Maeda S, Minagawa H, Takashima A, Maruyama W, Michikawa M, Yanagisawa K: A ganglioside-induced toxic soluble $A \beta$ assembly. Its enhanced formation from $A \beta$ bearing the Arctic mutation. J Biol Chem 2007, 282:2646-2655.

23. Hoshi M, Sato M, Matsumoto S, Noguchi A, Yasutake K, Yoshida N, Sato K: Spherical aggregates of $\beta$-amyloid (amylospheroid) show high neurotoxicity and activate tau protein kinase $1 /$ glycogen synthase kinase-3ß. Proc Natl Acad Sci USA 2003, 100:6370-6375.

24. Noguchi A, Matsumura S, Dezawa M, Tada M, Yanazawa M, Ito A, Akioka M, Kikuchi S, Sato M, Ideno S, Noda M, Fukunari A, Muramatsu S, Itokazu Y, Sato K, Takahashi H, Teplow DB, Nabeshima Y, Kakita A, Imahori K, Hoshi M: Isolation and characterization of patient-derived, toxic, high mass amyloid beta-protein (Abeta) assembly from Alzheimer disease brains. J Biol Chem 2009, 284:32895-905.

25. Tero R, Takizawa M, Li YJ, Yamazaki M, Urisu T: Lipid membrane formation by vesicle fusion on silicon dioide surfaces modified with alkyl selfassembled monolayer islands. Langmuir 2004, 20:7526-7531.

26. Kotilinek LA, Bacskai B, Westerman M, Kawarabayashi T, Younkin L, Hyman BT, Younkin S, Ashe KH: Reversible memory loss in a mouse model of Alzheimer's disease. J Neurosci 2002, 22:6331-6335.

27. Lee EB, Leng LZ, Zhang B, Kwong L, Trojanowski JQ, Lee VM: Targeting amyloid- $\beta$ peptide $(A \beta)$ oligomers by passive immunization with a conformation-selective monoclonal antibodies improves learning and memory in A $\beta$ precursor protein (APP) transgenic mice. J Biol Chem 2006, 281:4292-4299.

28. Mouri A, Noda Y, Hara H, Mizoguchi H, Tabira T, Nabeshim T: Oral vaccination with a viral vector containing $A \beta$ cDNA attenuates agerelated $A \beta$ accumulation and memory deficits without causing inflammation in a mouse Alzheimer model. FASEB J 2007, 21:2135-2148.

29. Schmued LC, Hopkins KJ, Fluoro-Jade B: A high affinity fluorescent marker for the localization of neuronal degeneration. Brain Res 2000, 874:123-130.

30. Lambert MP, Viola KL, Chromy BA, Chang L, Morgan TE, Yu J, Venton DL, Krafft GA, Finch CE, Klein WL: Vaccination with soluble $A \beta$ oligomers generates toxicity-neutralizing antibodies. J Neurochem 2001, 79:595-605.

31. Lambert MP, Barlow AK, Chromy BA, Edwards C, Freed R, Liosatos M, Morgan TE, Rozovsky I, Trommer B, Viola KL, Wals P, Zhang C, Finch CE, Lambert MP, Velasco PT, Chang L, Viola KL, Fernandez S, Lacor PN, Khuon D, Gong Y, Bigio EH, Shaw P, De Felice FG, Krafft GA, Klein WL: Monoclonal antibodies that target pathological assemblies of $A \beta$. J Neurochem 2007, 100:23-35.

32. Kawarabayashi T, Shoji M, Younkin LH, Wen-Lang L, Dickson DW, Murakami T, Matsubara E, Abe K, Ashe KH, Younkin SG: Dimeric amyloid beta protein rapidly accumulates in lipid rafts followed by apolipoprotein E and phosphorylated tau accumulation in the Tg2576 mouse model of Alzheimer's disease. J Neurosci 2004, 24:3801-3809.

33. Mori C, Spooner ET, Wisniewsk KE, Wisniewski TM, Yamaguch H, Saido TC, Tolan DR, Selkoe DJ, Lemere CA: Intraneuronal A 342 accumulation in Down syndrome brain. Amyloid 2002, 9:88-102.

34. Hu X, Crick SL, Bu G, Frieden C, Pappu RV, Lee JM: Amyloid seeds formed by cellular uptake, concentration, and aggregation of the amyloid-beta peptide. Proc Natl Acad Sci USA 2009, 106:20324-20329.

35. Tomiyama T, Matsuyama S, Iso H, Umeda T, Takuma H, Ohnishi K, Ishibashi K, Teraoka R, Sakama N, Yamashita T, Nishitsuji K, Ito K, Shimada H, Lambert MP, Klein WL, Mori H: A mouse model of amyloid beta oligomers: their contribution to synaptic alteration, abnormal tau phosphorylation, glial activation, and neuronal loss in vivo. J Neurosci 2010, 30:4845-56.

36. Matsubara E, Frangione B, Ghiso J: Characterization of apolipoprotein J-Alzheimer's A beta interaction. J Biol Chem 1995, 270:7563-7567.

doi:10.1186/1750-1326-6-20

Cite this article as: Takamura et al:: Extracellular and intraneuronal HMW-AbetaOs represent a molecular basis of memory loss in Alzheimer's disease model mouse. Molecular Neurodegeneration 2011 6:20. 